\title{
Concordance of Toxoplasma gondii Infection Markers Among Heterosexual Couples
}

\author{
Cosme Alvarado-Esquivel ${ }^{\mathrm{a}, \mathrm{d}}$, Sandy Janet Pacheco-Vega ${ }^{\mathrm{b}}$, Jesus Hernandez-Tinoco ${ }^{\mathrm{c}}$, \\ Luis Omar Berumen-Segovia ${ }^{a}$, Luis Francisco Sanchez-Anguiano ${ }^{c}$, Sergio Estrada-Martinez ${ }^{\mathrm{c}}$, \\ Ada Agustina Sandoval-Carrilloc, Jose Manuel Salas-Pacheco ${ }^{c}$, \\ Elizabeth Irasema Antuna-Salcido ${ }^{c}$
}

\begin{abstract}
Background: Very little is known about concordance of Toxoplasma gondii (T. gondii) infection markers among couples. Through a crosssectional study, we sought to determine the correlation of $T$. gondii infection in a sample of 119 heterosexual couples in Durango State, Mexico.
\end{abstract}

Methods: Participants were examined for the presence of anti-T. gondii IgG and IgM antibodies using enzyme-linked immunoassays. IgG and IgM seropositive couples were further analyzed for the presence of $T$. gondii DNA by using polymerase chain reaction (PCR).

Results: Anti-T. gondii IgG antibodies were found in 71 (59.7\%) men and in $63(52.9 \%)$ women (odds ratio $(\mathrm{OR})=1.31 ; 95 \%$ confidence interval (CI): $0.78-2.19 ; \mathrm{P}=0.29$ ). Of the 71 seropositive men, 40 $(56.3 \%)$ had a seropositive couple; in contrast, of the 63 seropositive women, $40(63.5 \%)$ had a seropositive couple $(\mathrm{OR}=0.74 ; 95 \% \mathrm{CI}$ : 0.37 - 1.48; $\mathrm{P}=0.39)$. In total, $65(54.6 \%)$ couples had concordant results (both IgG positive or both IgG negative), and 54 (45.4\%) had discordant results (a seropositive man with a seronegative woman, or a seropositive woman with a seronegative man) (kappa index $=0.08$; $95 \%$ CI: $-0.09-0.26)$. With respect to high (> $150 \mathrm{IU} / \mathrm{mL}$ ) levels of anti-T. gondii IgG antibodies, 79 (66.4\%) of the 119 couples had concordant results and $40(33.6 \%)$ had discordant results (kappa index $=$ -0.15 ; $95 \%$ CI: $-0.03-0.33)$. Forty couples were positive for anti- $T$. gondii IgM antibodies. Of them, 21 (52.5\%) had concordant results, and $19(47.5 \%)$ had discordant results (kappa index $=-0.01 ; 95 \% \mathrm{CI}$ : $-0.39-0.28)$. Concerning PCR, eight $(50 \%)$ of 16 couples were positive for $T$. gondii DNA. Of them, $11(68.8 \%)$ had concordant results, and five $(31.2 \%)$ had discordant results (kappa index $=0.31 ; 95 \% \mathrm{CI}$ :

Manuscript submitted June 25, 2017, accepted July 17, 2017

aBiomedical Research Laboratory, Faculty of Medicine and Nutrition, Juarez University of Durango State, Avenida Universidad S/N, 34000 Durango, Mexico

bSecretaria de Salud, Avenida Cuauhtemoc 225 norte, 34000 Durango, Mexico 'Institute for Scientific Research "Dr. Roberto Rivera-Damm", Juarez University of Durango State, Avenida Universidad S/N, 34000 Durango, Mexico ${ }^{\mathrm{d}}$ Corresponding Author: Cosme Alvarado-Esquivel, Laboratorio de Investigacion Biomedica, Facultad de Medicina y Nutricion, Avenida Universidad S/N, 34000 Durango, Dgo, Mexico. Email: alvaradocosme@yahoo.com

doi: https://doi.org/10.14740/jocmr3117w
$-0.17-0.79)$

Conclusions: Results suggest a poor concordance of serological and molecular markers of $T$. gondii infection among heterosexual couples. Further studies to confirm our results should be conducted.

Keywords: Toxoplasma gondii; Infection markers; Seroprevalence; Couples; Concordance; Epidemiology; Mexico

\section{Introduction}

The parasite Toxoplasma gondii (T. gondii) causes infections in humans and animals all around the world [1]. The disease caused by $T$. gondii is called toxoplasmosis, and it is characterized by the presence of chorioretinitis, lymphadenopathy, or meningoencephalitis [2]. A severe and life-threatening toxoplasmosis may occur in immunocompromised individuals infected with T. gondii [3]. Furthermore, infection with $T$. gondii in susceptible pregnant women may result in fetal infection leading to congenital toxoplasmosis [4]. Major routes for $T$. gondii infection include ingestion of food or water contaminated with oocysts shed by cats $[2,5]$, and by ingestion of raw or undercooked meat containing tissue cysts $[2,6]$. Less frequently, T. gondii infection may be acquired by blood transfusion [7], and organ transplantation [8].

It is unclear whether infection with $T$. gondii may be sexually transmitted. Studies by Janitschke and Nurnberger in humans and animals showed that sexual transmission of $T$. gondii did not have epidemiological significance [9]. In contrast, Flegr et al have hypothesized that toxoplasmosis can be a sexually transmitted infection [10]. Light-microscopic evidence of $T$. gondii in testes of autopsy cases of patients with acquired immunodeficiency syndrome and systemic opportunistic infections was provided [11]. In a study of psychiatric patients, sexual promiscuity was shown to be associated with $T$. gondii infection [12]. In addition, a high seroprevalence of $T$. gondii infection was found in female sex workers in an age- and gender-matched case-control study [13]. In a recent study, Singh et al found a significantly higher prevalence of toxoplasmosis in married women than in unmarried women [14]. On the other hand, experimental infections with $T$. gondii in animals have shown conflicting results on sexual transmission. Lopes et al 
demonstrated sexual transmission of $T$. gondii in sheep with vertical transmission to their lambs [15]. In contrast, experiments in mice showed that toxoplasmosis could not be transmitted to female mice and their offspring due to mating with infected male mice [16]. We are aware of only one study that determined the seroconcordance of $T$. gondii infection in human couples. In an article published in 1969, Price reported a poor seroconcordance of anti-T. gondii antibodies among 43 married couples using the dye test [17]. In the present study, we sought to determine the correlation of $T$. gondii infection among heterosexual couples in Durango, Mexico using serological and molecular methods.

\section{Materials and Methods}

\section{Study design and couples studied}

Through a cross-sectional study design, 119 heterosexual couples who were either married or living together were examined. All participants were inhabitants of the rural San Dimas Municipality, in Durango State, Mexico. Couples were enrolled consecutively when attending medical consultations provided by a rural mobile medical unit of the Secretary of Health. Couples were enrolled in the study from December 2015 to August 2016. Inclusion criteria were couples either married or living together, each participant aged 18 years and older, and who accepted to participate in the study. Participants were $15-80$ (mean: $41.1 \pm 14.1$ ) years old. Men were 20 - 78 (mean: 43.36 \pm 14.2 ) years old, whereas women were 15 - 80 (mean: 38.6 \pm 13.6 ) years old. Duration of cohabitation in the 119 couples studied was: less than 3 years in $31(26.1 \%)$, between 3 and 6 years in $48(40.3 \%)$, and more than 6 years in $40(33.6 \%)$.

\section{Detection of T. gondii IgG and IgM antibodies}

Participants were firstly examined for the presence of anti- $T$. gondii IgG and those who were positive for this test were further examined for IgM antibodies. Sera of participants were analyzed for anti-T. gondii IgG antibodies with the commercially available enzyme immunoassay kit "Toxoplasma IgG" (Diagnostic Automation Inc., Woodland Hills, CA, USA). Levels of anti-T. gondii IgG antibody were expressed as International Units (IU)/mL, and a cutoff $\geq 8 \mathrm{IU} / \mathrm{mL}$ was considered for seropositivity. Anti-T. gondii $\operatorname{IgM}$ antibodies were detected by the commercially available enzyme immunoassay "Toxoplasma IgM" kit (Diagnostic Automation Inc.). All assays were performed following the instructions of the manufacturer. Positive and negative controls included in the kits were run in each assay.

\section{DNA extraction and detection of $T$. gondii DNA}

Couples with $T$. gondii-specific $\operatorname{IgG}$ and IgM antibodies by enzyme immunoassay were further examined for $T$. gondii DNA by nested-polymerase chain reaction (PCR). DNA ex- traction from whole blood of seropositive participants was performed following a protocol described elsewhere (http:// www.protocol-online.org/prot/Protocols/Rapid-Extraction-ofHigh-Quality-DNA-from-Whole-Blood-Stored-at-4-C-forLong-Period-4175.html). Amplification of DNA was carried out with primers directed against the B1 gene of $T$. gondii and following the protocol described by Roth et al [18]. Amplification products were run in a $2 \%$ agarose gel electrophoresis, then stained with ethidium bromide, and visualized with an ultraviolet transilluminator.

\section{Statistical analysis}

We performed the statistical analysis with the software SPSS version 15.0 (SPSS Inc. Chicago, IL). We measured the agreement between seropositivity rates among couples by the Cohen test using the kappa index. Statistical significance was set at a $P$ value $<0.05$.

\section{Ethics statement}

The Ethical Committee of the General Hospital of the Secretary of Health in Durango City approved this project. The purpose and procedures of this study were explained to all participants, and a written informed consent was obtained from all of them.

\section{Results}

In the 119 couples studied, anti-T. gondii IgG antibodies were found in $71(59.7 \%)$ men and in $63(52.9 \%)$ women (odds ratio $(\mathrm{OR})=1.31 ; 95 \%$ confidence interval $(\mathrm{CI}): 0.78-2.19$; $\mathrm{P}=0.29)$. Of the 71 seropositive men, $40(56.3 \%)$ had a seropositive couple; in contrast, of the 63 seropositive women, $40(63.5 \%)$ had a seropositive couple $(\mathrm{OR}=0.74 ; 95 \% \mathrm{CI}$ : $0.37-1.48 ; \mathrm{P}=0.39)$. Thus, in $40(33.6 \%)$ of the 119 couples, both men and women were seropositive for anti-T. gondii IgG antibodies. Whereas in 25 (21\%) of the 119 couples studied, both men and women were seronegative for anti-T. gondii IgG antibodies. In total, of the 119 couples, 65 (54.6\%) had concordant results (both IgG positive or both IgG negative), and $54(45.4 \%)$ had discordant results (a seropositive man with a seronegative woman, or a seropositive woman with a seronegative man). Analysis of concordance of IgG seropositivity among couples showed a poor agreement (kappa index $=0.08$; 95\% CI: $-0.09-0.26$ ) (Table 1). The frequency of anti-T. gondii $\mathrm{IgG}$ antibodies was similar $(\mathrm{P}=0.89)$ in couples with less than 3 years of relationship $(14 / 31,45.2 \%)$ to those with $3-6$ years $(9 / 48,18.8 \%)$ or with more than 6 years $(17 / 40,42.5 \%)$.

Of the 119 couples studied, $52(43.7 \%)$ had at least one member with high (>150 IU/mL) anti-T. gondii IgG antibody levels. In 12 couples both members had high antibody levels, whereas in 67 both members did not have high antibody levels. Because of this increase in the number $(n=67)$ of couples with antibody levels equal to or lower than $150 \mathrm{IU} / \mathrm{mL}$, 
Table 1. Extent of Agreement of Seropositivity to Anti-T. gondii IgG Antibodies Among Couples

\begin{tabular}{|c|c|c|c|c|c|c|}
\hline \multirow[b]{2}{*}{ Men } & \multicolumn{2}{|c|}{ Women } & \multirow[b]{2}{*}{ Total } & \multirow[b]{2}{*}{ Kappa index } & \multirow[b]{2}{*}{$95 \%$ CI } & \multirow[b]{2}{*}{ P-value } \\
\hline & $\begin{array}{l}\text { Exposed } \\
\text { (T. gondii IgG positive) }\end{array}$ & $\begin{array}{l}\text { Unexposed } \\
\text { (T. gondii IgG negative) }\end{array}$ & & & & \\
\hline Exposed (T. gondii IgG positive) & 40 & 31 & 71 & & & \\
\hline Unexposed ( $T$. gondii IgG negative) & 23 & 25 & 48 & & & \\
\hline Total & 63 & 56 & 119 & 0.08 & $-0.09-0.26$ & 0.36 \\
\hline
\end{tabular}

Table 2. Extent of Agreement of High (> $150 \mathrm{IU} / \mathrm{mL}$ ) Anti-T. gondii IgG Antibody Levels Among Couples

\begin{tabular}{|c|c|c|c|c|c|c|}
\hline \multirow[b]{2}{*}{ Men } & \multicolumn{2}{|c|}{ Women } & \multirow[b]{2}{*}{ Total } & \multirow[b]{2}{*}{ Kappa index } & \multirow[b]{2}{*}{$95 \%$ CI } & \multirow[b]{2}{*}{ P-value } \\
\hline & $\begin{array}{l}\text { Exposed (high levels } \\
\text { of } T \text {. gondii IgG) }\end{array}$ & $\begin{array}{l}\text { Unexposed (no high } \\
\text { levels of } T \text {. gondii IgG) }\end{array}$ & & & & \\
\hline Exposed (high levels of $T$. gondii $\operatorname{IgG}$ ) & 12 & 16 & 28 & & & \\
\hline Unexposed (no high levels of $T$. gondii IgG) & 24 & 67 & 91 & & & \\
\hline Total & 36 & 83 & 119 & 0.15 & $\begin{array}{l}-0.03- \\
0.33\end{array}$ & 0.09 \\
\hline
\end{tabular}

the rate of concordance increased. Thus, 79 (66.4\%) of the 119 couples had concordant results (both with high antibody levels or both with lower antibody levels or seronegative). Whereas $40(33.6 \%)$ of the 119 couples had discordant results (a man with high antibody levels with a woman with lower antibody levels or seronegative; or a woman with high antibody levels with a man with lower antibody levels or seronegative). Analysis of concordance of high IgG antibody levels among couples showed a poor agreement (kappa index $=-0.15 ; 95 \%$ CI: -0.03 - 0.33) (Table 2). The frequencies of high anti-T. gondii IgG antibody levels were similar $(\mathrm{P}=0.49)$ in couples with less than 3 years of relationship $(6 / 31,19.4 \%)$ and those with $3-6$ years $(10 / 48,20.8 \%)$ or with more than 6 years $(12 / 40,30.0 \%)$.

Anti-T. gondii IgM antibodies were found in 51 (38.1\%) of the 134 individuals with anti- $T$. gondii IgG antibodies. Of them, $28(54.9 \%)$ were found in men and $23(45.1 \%)$ in women. In total, one or two members of 40 couples were positive for anti-T. gondii IgM antibodies. Of these 40 seropositive couples, 21 (52.5\%) had concordant results (both IgM positive or both IgM negative), and 19 (47.5\%) had discordant results (a seropositive man with a seronegative woman, or a seropositive woman with a seronegative man). Analysis of concordance of IgM seropositivity among IgG seropositive couples showed a poor agreement (kappa index $=-0.01 ; 95 \% \mathrm{CI}:-0.39$ - 0.28) (Table 3). Among the $40 \mathrm{IgG}$ seropositive couples, the frequency of anti-T. gondii $\operatorname{IgM}$ antibodies was similar $(\mathrm{P}=$
$0.77)$ in couples with less than 3 years of relationship $(5 / 14$, $35.7 \%)$ to those with $3-6$ years $(4 / 9,44.4 \%)$ or with more than 6 years $(7 / 17,41.2 \%)$.

Detection of $T$. gondii DNA by PCR was performed in the 16 couples with anti-T. gondii IgM antibodies. T. gondii DNA was found in a man or a woman or both in eight $(50 \%)$ of these 16 couples. Of them, $11(68.8 \%)$ had concordant results (both PCR positive or both PCR negative), and five (31.2\%) had discordant results (a PCR positive man with a PCR negative woman, or a PCR positive woman with a PCR negative man). Analysis of concordance of $T$. gondii DNA positivity among these couples showed a fair agreement (kappa index $=0.31$; 95\% CI: $-0.17-0.79$ ).

\section{Discussion}

Whether $T$. gondii infection can be transmitted among couples is poorly understood. Therefore, we sought to determine the concordance of $T$. gondii infection markers among heterosexual couples. We found poor agreements in seropositivity of anti- $T$. gondii IgG antibodies (Cohen's kappa $=0.08$ ), in high anti-T. gondii $\operatorname{IgG}$ antibody levels (Cohen's kappa $=-0.15$ ), and in seropositivity of anti-T. gondii IgM antibodies (Cohen's kappa $=-0.01)$ among couples. In addition, a fair agreement in positivity to $T$. gondii DNA among IgM seropositive cou-

Table 3. Extent of Agreement of Anti-T. gondii IgM Antibodies in Anti-T. gondii IgG Seropositive Couples

\begin{tabular}{|c|c|c|c|c|c|c|}
\hline \multirow[b]{2}{*}{ Men } & \multicolumn{2}{|c|}{ Women } & \multirow[b]{2}{*}{ Total } & \multirow[b]{2}{*}{ Kappa index } & \multirow[b]{2}{*}{$95 \% \mathrm{CI}$} & \multirow[b]{2}{*}{ P-value } \\
\hline & $\begin{array}{l}\text { Exposed (Anti-T. } \\
\text { gondii IgM positive) }\end{array}$ & $\begin{array}{l}\text { Unexposed (Anti-T. } \\
\text { gondii IgM negative) }\end{array}$ & & & & \\
\hline Unexposed (anti- $T$. gondii IgM negative) & 12 & 5 & 17 & & & \\
\hline Total & 28 & 12 & 40 & -0.01 & $-0.39-0.28$ & 0.94 \\
\hline
\end{tabular}


ples was found (kappa index $=0.31 ; 95 \%$ CI: $-0.17-0.79$ ). Thus, we found a poor concordance of serological (presence of $\mathrm{IgG}$, high levels of $\mathrm{IgG}$, and presence of $\operatorname{IgM}$ ) and molecular (PCR) markers of $T$. gondii infection among couples. None of the serological markers correlated with the duration of the relationship among couples. Our results suggest that clustering of infection with $T$. gondii among couples within the community studied may not be attributable to intrafamilial transmission. Several routes for $T$. gondii infection might occur in people living in the same home including cleaning cat feces, contact with soil, and consumption of water or food. In addition, heterosexual intercourse might be an additional intrafamilial route for $T$. gondii infection. The lack of concordance in markers of $T$. gondii infection among couples was unexpected because several previous observations suggest a likely sexual transmission of $T$. gondii infection. For instance, a light-microscopic evidence of testicular infection with $T$. gondii in autopsy cases with acquired immunodeficiency syndrome was provided [11]. It is likely that the presence of $T$. gondii in testes occur only in immunocompromised individuals. In the present study, apparently healthy individuals were enrolled and $T$. gondii-infected subjects were likely immunocompetent and perhaps no parasite dissemination to genital organs occurred. In a recent ageand gender-matched case-control study, a high rate of T. gondii infection was found in female sex workers [13]. It is possible that a higher frequency of sexual contacts and diversity of partners in female sex workers than those in women of the present study might account for an increase in the likelihood for a $T$. gondii sexual transmission. In another study, married women had a higher seroprevalence of $T$. gondii infection than single women in India [14]. However, researchers found an increase of seroprevalence with age in the studied women [14]. Perhaps differences in ages might explain differences in seroprevalences between married and single women. Married women could be older than single women and further studies, i.e. matched case-control studies, may confirm an association between $T$. gondii exposure and a married status. A hypothesis was made recently that toxoplasmosis is transmitted from infected men to non-infected women during unprotected sexual intercourse [10]. Results of the present study cannot support this hypothesis because no agreement in serological and molecular markers of $T$. gondii infection among couples was found. In addition, no difference in seroprevalence among men and women was found. In a further study, infection with $T$. gondii was associated with sexual promiscuity in psychiatric patients [12]. It is possible that, as occurs in female sex workers, a higher frequency of sexual contacts and diversity of partners in psychiatric patients with sexual promiscuity than in subjects of the present study might account for an increase in the likelihood for a sexual transmission of $T$. gondii. In a study in animals, $T$. gondii was isolated from semen of $T$. gondii infected sheep and researchers demonstrated a sexual transmission of $T$. gondii in sheep with consequent vertical transmission to their lambs [15]. In contrast, a study in mice found a lack of transmission of $T$. gondii to female mice and their offspring due to mating [16]. In addition, in a study using a mouse inoculation test, $T$. gondii could not be cultured from ejacula and biopsies specimens of the testicles of men from childless marriages [9].

This study has some limitations. The sample size is rela- tively small, and we studied people from only one community. No genotyping of T. gondii DNA was performed. Further studies should include a larger sample size of couples, of several communities, and perform genotyping of $T$. gondii DNA.

We conclude that there is poor concordance of serological and molecular markers of $T$. gondii infection among heterosexual couples in the northern Mexican state of Durango. Further studies to confirm our results should be conducted.

\section{Conflicts of Interest}

The authors declare that there are no conflicts of interest regarding the publication of this paper.

\section{Grant Support}

This study was financially supported by Secretary of Public Education, Mexico (grant No. DSA/103.5/14/11311), and Juarez University of Durango State.

\section{References}

1. Dubey JP. Toxoplasmosis of animals and humans, second edition. Boca Raton, Florida: CRC Press, 2010.

2. Montoya JG, Liesenfeld O. Toxoplasmosis. Lancet. 2004;363(9425):1965-1976.

3. Machala L, Kodym P, Maly M, Geleneky M, Beran O, Jilich D. [Toxoplasmosis in immunocompromised patients]. Epidemiol Mikrobiol Imunol. 2015;64(2):59-65.

4. Kravetz J. Congenital toxoplasmosis. BMJ Clin Evid. 2013;2013.

5. Torrey EF, Yolken RH. Toxoplasma oocysts as a public health problem. Trends Parasitol. 2013;29(8):380-384.

6. Belluco S, Mancin M, Conficoni D, Simonato G, Pietrobelli M, Ricci A. Investigating the Determinants of Toxoplasma gondii Prevalence in Meat: A Systematic Review and Meta-Regression. PLoS One. 2016;11(4):e0153856.

7. Foroutan-Rad M, Majidiani H, Dalvand S, Daryani A, Kooti W, Saki J, Hedayati-Rad F, et al. Toxoplasmosis in Blood Donors: A Systematic Review and Meta-Analysis. Transfus Med Rev. 2016;30(3):116-122.

8. Filloy A, Garcia-Garcia O, Fernandez-Lorente L. Chorioretinitis as the first sign of acquired toxoplasmosis transmitted from donor following kidney transplantation: case report and review of the literature. Ocul Immunol Inflamm. 2013;21(1):34-35.

9. Janitschke K, Nurnberger F. [Studies on the significane of sexual intercourse for the transmission of Toxoplasma gondii (author's transl)]. Zentralbl Bakteriol Orig A. 1975;231(1-3):323-332.

10. Flegr J, Klapilova K, Kankova S. Toxoplasmosis can be a sexually transmitted infection with serious clinical consequences. Not all routes of infection are created equal. Med Hypotheses. 2014;83(3):286-289.

11. De Paepe ME, Guerrieri C, Waxman M. Opportunistic 
infections of the testis in the acquired immunodeficiency syndrome. Mt Sinai J Med. 1990;57(1):25-29.

12. Alvarado-Esquivel C, Alanis-Quinones OP, Arreola-Valenzuela MA, Rodriguez-Briones A, Piedra-Nevarez LJ, Duran-Morales E, Estrada-Martinez S, et al. Seroepidemiology of Toxoplasma gondii infection in psychiatric inpatients in a northern Mexican city. BMC Infect Dis. 2006;6:178.

13. Alvarado-Esquivel C, Sanchez-Anguiano LF, Hernandez-Tinoco J, Arreola-Chaidez E, Lopez J, Salcido-Meraz KI, Estrada-Martinez S, et al. High seroprevalence of toxoplasma gondii infection in female sex workers: a case-control study. Eur J Microbiol Immunol (Bp). 2015;5(4):285-292.

14. Singh S, Munawwar A, Rao S, Mehta S, Hazarika NK. Serologic prevalence of Toxoplasma gondii in Indian women of child bearing age and effects of social and environmental factors. PLoS Negl Trop Dis. 2014;8(3):e2737.

15. Lopes WD, Rodriguez JD, Souza FA, dos Santos TR, dos Santos RS, Rosanese WM, Lopes WR, et al. Sexual transmission of Toxoplasma gondii in sheep. Vet Parasitol. 2013;195(1-2):47-56.

16. Asgari Q, Keshavarz Valian H, Rezaeian M, Shojaee S, Mehrabani D. Toxoplasma gondii: sexual transmission in mice. J Parasit Dis. 2015;39(2):253-257.

17. Price JH. Toxoplasma infection in an urban community. Br Med J. 1969;4(5676):141-143.

18. Roth A, Roth B, Hoffken G, Steuber S, Khalifa KI, Janitschke K. Application of the polymerase chain reaction in the diagnosis of pulmonary toxoplasmosis in immunocompromised patients. Eur J Clin Microbiol Infect Dis. 1992;11(12):1177-1181. 